\title{
The Solubility of $\mathrm{MgO}$ in Molten $\mathrm{MgCl}_{2}-\mathrm{CaCl}_{2}$ Salt
}

\author{
Masaaki Ito* and Kazuki Morita \\ Department of Materials Engineering, The University of Tokyo, Tokyo 113-8656, Japan
}

The solubility of $\mathrm{MgO}$ in molten $\mathrm{MgCl}_{2}$ and $\mathrm{CaCl}_{2}$ has been studied. In pure $\mathrm{MgCl}_{2}$, the $\mathrm{MgO}$ solubility was determined to be $0.63-$ $2.90 \mathrm{~mol} \%$ at $1073-1373 \mathrm{~K}$, while $0.24-0.63 \mathrm{~mol} \%$ in pure $\mathrm{CaCl}_{2}$ at $1223-1523 \mathrm{~K}$. The effects of $\mathrm{MgCl}_{2}$ and $\mathrm{CaO}$ addition to $\mathrm{CaCl} 2$ were investigated, and the solubility product of $\mathrm{MgO}$ was found to increase with the amount of $\mathrm{MgCl}_{2}$ addition, while CaO addition did not affect significantly. They were explained in terms of the activity coefficient of oxide ion $\left(\mathrm{O}^{2-}\right)$ as well as the enthalpy of mixing for the $\mathrm{MgO}^{-\mathrm{CaCl}} \mathrm{C}_{2}$ system. From the experimental results, the corrosion possibility of $\mathrm{MgO}$ refractory by $\mathrm{Cl}$-containing gas was considered.

(Received April 21, 2004; Accepted June 11, 2004)

Keywords: molten salt, solubility product, thermodynamics, $\mathrm{MgO}$ refractory, corrosion

\section{Introduction}

Recently, waste plastics have been recycled in iron and steel making processes. One of the processes is to inject the plastics into the blast furnace with pulverized coal. ${ }^{1)}$ The plastics containing chlorine, e.g. PVC, is separated, or used after removing chlorine in the process ${ }^{2)}$ due to the problem of dioxin and $\mathrm{HCl}$ generation. It is necessary to grasp the reactions between refractories and chlorine bearing gas in order to evaluate the effect of chlorine contamination in such high temperature processes.

Hirosumi et al. ${ }^{3)}$ and Miwa et ll. $^{4)}$ studied the dissolution mechanism of chlorine in the oxide melt. They clarified chlorine dissolved into molten oxides as $\mathrm{Cl}^{-}$ion, and discussed the distribution of chlorine between molten oxides and gas phase. Accordingly, it is impatient to predict the possibility of corrosion of refractories by $\mathrm{Cl}$-containing gas generated in the furnace. However, there is no research about the reaction between $\mathrm{Cl}$-containing gas and refractory.

Chlorine is likely to exist as $\mathrm{HCl}, \mathrm{CaCl}_{2}, \mathrm{MgCl}_{2}$ etc. in the high temperature furnace. When $\mathrm{MgO}$ is a major refractory component, we can consider some types of corrosions such as the reaction between $\mathrm{MgO}$ and $\mathrm{HCl}$ gas and the dissolution of $\mathrm{MgO}$ in a molten chloride condensed at low temperature area.

Hence, the solubility of $\mathrm{MgO}$ in $\mathrm{MgCl}_{2}-\mathrm{CaCl}_{2}$ melt becomes important because $\mathrm{MgO}$ can be corroded by $\mathrm{HCl}$ even when the activity of $\mathrm{MgCl}_{2}$ is smaller than unity with a considerable solubility of $\mathrm{MgO}$ in $\mathrm{MgCl}_{2}$. When the solubility of $\mathrm{MgO}$ in $\mathrm{CaCl}_{2}$ melt is large, the $\mathrm{MgO}$ based refractory will be corroded with smaller activity of $\mathrm{CaCl}_{2}$ in the melt than that for the deposition of its condensed phases.

For the reasons, the solubility of $\mathrm{MgO}$ in the molten $\mathrm{MgCl}_{2}-\mathrm{CaCl}_{2}$ system play an important role in the evaluation of the reactions. Although there are a few available data of the system, ${ }^{5-7)}$ there is no data at the desired temperature. In the present research, we measured the solubility of $\mathrm{MgO}$ in molten $\mathrm{MgCl}_{2}$ or molten $\mathrm{CaCl}_{2}$, and discussed the thermodynamics of the $\mathrm{MgO}-\mathrm{CaCl}_{2}$ system. Based on the measurement, we investigated the possibility of corrosion of $\mathrm{MgO}$ based refractory on some assumptions.

\section{Experimental}

Fused $\mathrm{MgO}$ and reagent grade $\mathrm{MgCl}_{2}$ and/or $\mathrm{CaCl}_{2}$ powder, which were dried at $473 \mathrm{~K}$ for $3 \mathrm{~h}$, were charged into the graphite crucible, and the crucible and graphite lid were sealed with alumina paste. Reagent grade $\mathrm{MgO}$ and $\mathrm{CaO}$ calcined from reagent grade $\mathrm{CaCO}_{3}$ at $1173 \mathrm{~K}$ were added to the crucible when the initial oxygen content was adjusted. The crucible was kept in a hot zone of the furnace.

A $\mathrm{SiC}$ resistance furnace with a fused mullite tube was employed and experimental temperature (1073-1523 K) was controlled by a proportional integral differential (PID) controller and kept within $\pm 1 \mathrm{~K}$ with a Pt-6\%Rh/Pt$30 \% \mathrm{Rh}$ thermocouple. Schematic sketch inside the furnace is drawn in Fig. 1.

During experiment, purified Ar gas was flown onto the crucible at a rate of about $100 \mathrm{Ncm}^{3} / \mathrm{min}$ in order to prevent its oxidation. In the gas purification system, $\mathrm{P}_{2} \mathrm{O}_{5}$, soda lime and $\mathrm{Mg}$ flake at $823 \mathrm{~K}$ were used to remove $\mathrm{H}_{2} \mathrm{O}, \mathrm{CO}_{2}$ and $\mathrm{O}_{2}$, respectively.

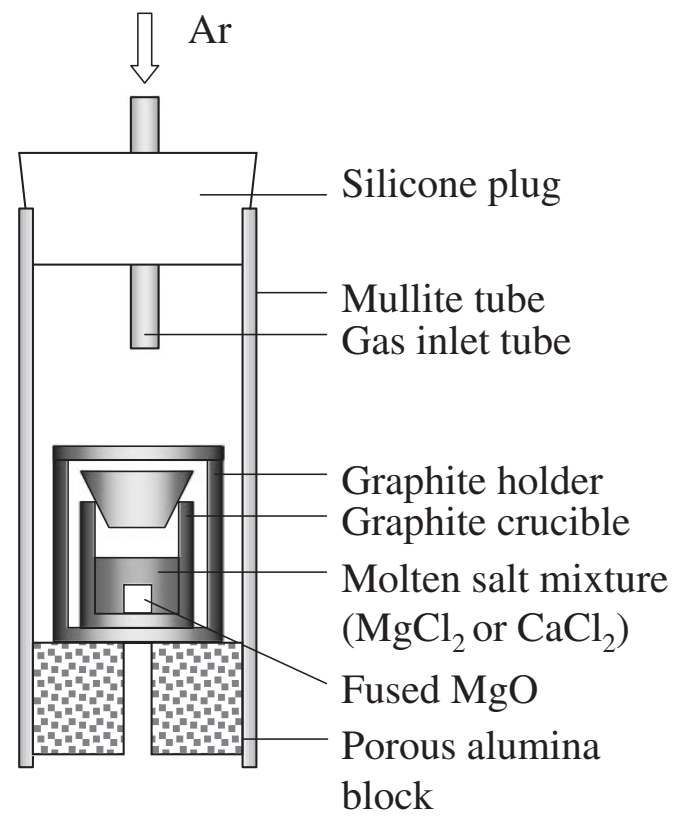

Fig. 1 Schematic cross section of the experimental apparatus. 
Table 1 Solubility of $\mathrm{MgO}$ in molten $\mathrm{MgCl}_{2}$.

\begin{tabular}{|c|c|c|c|c|c|c|}
\hline \multirow[t]{2}{*}{ No. } & \multirow[t]{2}{*}{ Temp. (K) } & \multirow[t]{2}{*}{ Time (h) } & \multirow{2}{*}{$\begin{array}{c}\begin{array}{c}\text { Initial } \\
\text { concentration }\end{array} \\
X_{\mathrm{O}^{2-}}{ }^{0} \times 10^{2}\end{array}$} & \multicolumn{2}{|c|}{$\begin{array}{l}\text { Equilibrium } \\
\text { concentration }\end{array}$} & \multirow[t]{2}{*}{$\ln X_{\mathrm{Mg}^{2+}} X_{\mathrm{O}^{2-}}$} \\
\hline & & & & $X_{\mathrm{O}^{2-}} \times 10^{2}$ & $X_{\mathrm{Mg}^{2+}} \times 10^{2}$ & \\
\hline $1-2$ & 1173 & 3 & 0.18 & 0.72 & 100 & -4.93 \\
\hline $1-3$ & 1173 & 3 & 0.18 & 0.70 & 100 & -4.97 \\
\hline $1-4$ & 1273 & 3 & 0.34 & 1.08 & 100 & -4.53 \\
\hline $1-5$ & 1373 & 3 & 0 & 1.47 & 100 & -4.22 \\
\hline
\end{tabular}

The experimental time was determined to be $3 \mathrm{~h}$ for the $\mathrm{MgO}-\mathrm{MgCl}_{2}$ system and $15 \mathrm{~h}$ or $24 \mathrm{~h}$ for the $\mathrm{MgO}-\mathrm{CaCl}_{2}$ system, which were confirmed to be enough for the equilibrium attainment by the preliminary experiment. After the experiment, the sample was withdrawn and quenched in the flushing Ar gas and subjected to chemical analyses.

The $\mathrm{Ca}$ and $\mathrm{Mg}$ contents of the samples were determined by inductively coupled plasma (ICP) emission spectrometry at the wavelengths of 318 and $279 \mathrm{~nm}$, respectively. The oxygen content of the samples was determined by the following method. The grounded samples were dissolved in a certain amount of dilute hydrochloric acid (1/10 or $1 / 100$ $\mathrm{mol} / \mathrm{l})$, then the excess acid was back-titrated with $1 / 10$ or $1 /$ $100 \mathrm{~mol} / 1 \mathrm{NaOH}$ aqueous solution using a phenolphthalein indicator, where $\mathrm{HCl}$ was consumed by the reaction (1).

$$
\mathrm{AO}+2 \mathrm{HCl}=\mathrm{ACl}_{2}+\mathrm{H}_{2} \mathrm{O}
$$

Here in eq. (1), A represents the element, $\mathrm{Ca}$ or $\mathrm{Mg}$.

\section{Results}

\subsection{The $\mathrm{MgO}-\mathrm{MgCl}_{2}$ system}

In order to determine experimental time, the time dependence of $\mathrm{MgO}$ solubility in molten $\mathrm{MgCl}_{2}$ was measured at $1373 \mathrm{~K}$ as shown in Fig. 2, where $\mathrm{O}^{2-}$ content in molten $\mathrm{MgCl}_{2}$ was regarded as the amount of $\mathrm{MgO}$ dissolved. The equilibration time was found to be less than $3 \mathrm{~h}$ from the result, hence the experimental time determined to be $3 \mathrm{~h}$.

The solubility of $\mathrm{MgO}$ in $\mathrm{MgCl}_{2}$ melt was measured at 1073-1373 K. Experimental conditions and results are summarized in Table 1 and Fig. 3. The solubility of $\mathrm{MgO}$ was from $0.63 \mathrm{~mol} \%$ to $2.90 \mathrm{~mol} \%$ at $1073-1373 \mathrm{~K}$.

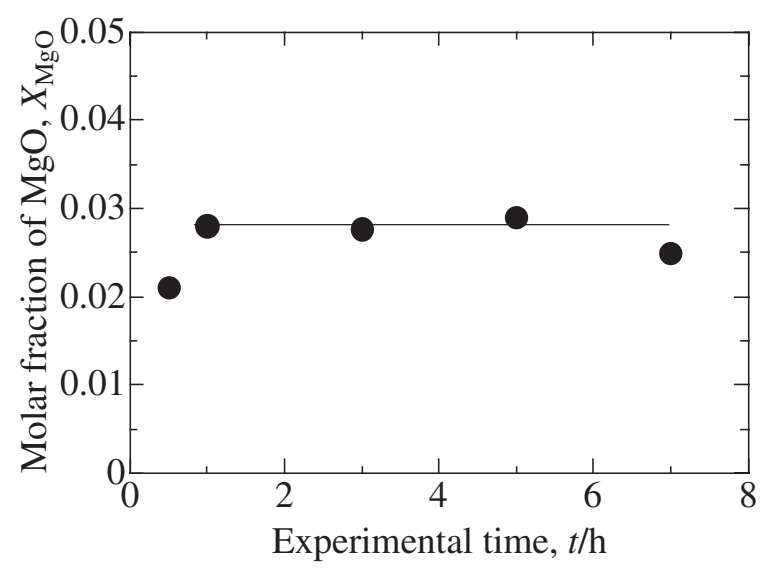

Fig. 2 Time dependence of the $\mathrm{MgO}$ solubility in molten $\mathrm{MgCl}_{2}$ at $1373 \mathrm{~K}$.

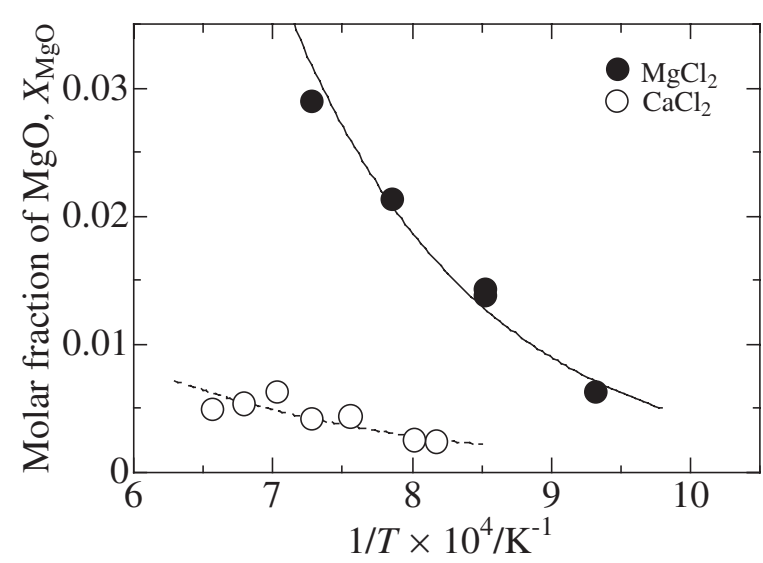

Fig. 3 Temperature dependence of the $\mathrm{MgO}$ solubility in molten $\mathrm{MgCl}_{2}$ or molten $\mathrm{CaCl}_{2}$.

In the present work, the degree of freedom for the $\mathrm{MgO}$ $\mathrm{MgCl}_{2}$ system at a certain temperature is equal to zero, whereas that for the $\mathrm{MgO}-\mathrm{CaCl}_{2}$ system becomes to one. Accordingly, the $\mathrm{MgO}$ solubility was evaluated by the solubility product shown in eq. (2) for the $\mathrm{MgO}-\mathrm{CaCl}_{2}$ system together with that of the $\mathrm{MgO}-\mathrm{MgCl}_{2}$ system for comparison.

$$
K_{\mathrm{sp}}(\mathrm{MgO})=X_{\mathrm{Mg}^{2+}} X_{\mathrm{O}^{2-}}
$$

Here $X_{\mathrm{Mg}^{2+}}$ and $X_{\mathrm{O}^{2-}}$ are the cation fraction of $\mathrm{Mg}^{2+}$ and the anion fraction of $\mathrm{O}^{2-}$, respectively, which are defined as eq. (3),

$$
X_{\mathrm{Mg}^{2+}}=\frac{n_{\mathrm{Mg}^{2+}}}{n_{\mathrm{Mg}^{2+}}+n_{\mathrm{Ca}^{2+}}}, \quad X_{\mathrm{O}^{2-}}=\frac{n_{\mathrm{O}^{2-}}}{n_{\mathrm{O}^{2-}}+n_{\mathrm{Cl}^{-}}}
$$

where $n_{\mathrm{i}}$ is the number of moles of $\mathrm{i}$ ion in the melt.

The solubility product of $\mathrm{MgO}$ in molten $\mathrm{MgCl}_{2}$ is shown in Fig. 4 together with calculated from the data of Mediaas et $a l .{ }^{7)}$ Its temperature dependence was obtained as eq. (4).

$$
\ln K_{\mathrm{sp}}(\mathrm{MgO})=-\frac{7400}{T}+1.26
$$

\subsection{The $\mathrm{MgO}-\mathrm{CaCl}_{2}$ system}

In order to determine the experimental time for equilibration, $\mathrm{MgO}$ solubilities in molten $\mathrm{CaCl}_{2}$ at various experimental time was measured at $1223 \mathrm{~K}$ and $1323 \mathrm{~K}$ as shown in Fig. 5, where $\mathrm{Mg}^{2+}$ content in molten $\mathrm{CaCl}_{2}$ was regarded as the amount of $\mathrm{MgO}$ dissolved. The experimental time was determined to be $15 \mathrm{~h}$ at $1223-1323 \mathrm{~K}$ and $24 \mathrm{~h}$ at the temperature higher than $1323 \mathrm{~K}$ from the results. 


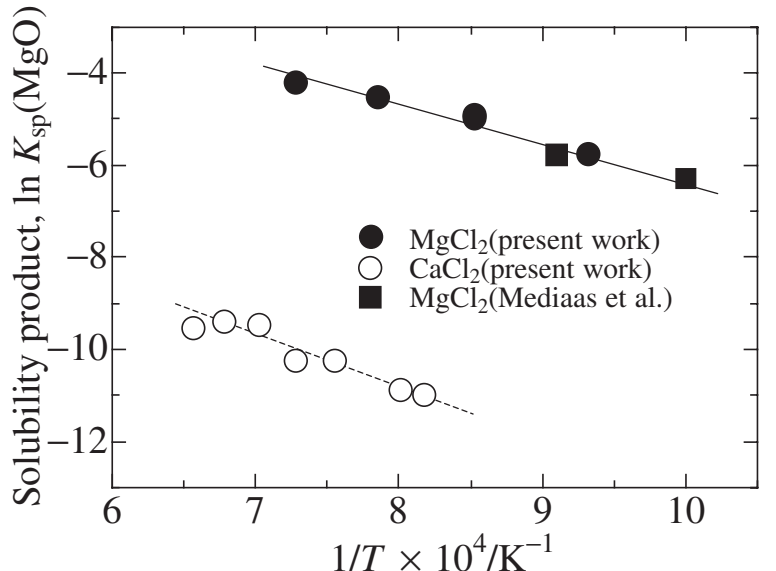

Fig. 4 Temperature dependence of the solubility product of $\mathrm{MgO}$ in molten $\mathrm{MgCl}_{2}$ or molten $\mathrm{CaCl}_{2}$.

The solubility of $\mathrm{MgO}$ in $\mathrm{CaCl}_{2}$ melt was measured at $1223-1523 \mathrm{~K}$. Experimental conditions and results are summarized in Table 2 and Fig. 3. The solubility of $\mathrm{MgO}$ increased from $0.24 \mathrm{~mol} \%$ to $0.63 \mathrm{~mol} \%$ with increasing temperature from $1223 \mathrm{~K}$ to $1523 \mathrm{~K}$.

As mentioned above, the solubility of $\mathrm{MgO}$ in molten $\mathrm{CaCl}_{2}$ should be evaluated in terms of the solubility product in the present work. The temperature dependence of the solubility product of $\mathrm{MgO}$ is shown in Fig. 4, and it can be approximated by eq. (5).

$$
\ln K_{\mathrm{sp}}(\mathrm{MgO})=-\frac{10400}{T}-2.44
$$

\subsection{The $\mathrm{MgO}-\mathrm{CaCl}_{2}(-\mathrm{CaO})$ and $\mathrm{MgO}-\mathrm{CaCl}_{2}\left(-\mathrm{MgCl}_{2}\right)$ systems}

The solubility product of $\mathrm{MgO}$ in the $\mathrm{CaCl}_{2}$ melt showed the considerably smaller value between the previous two

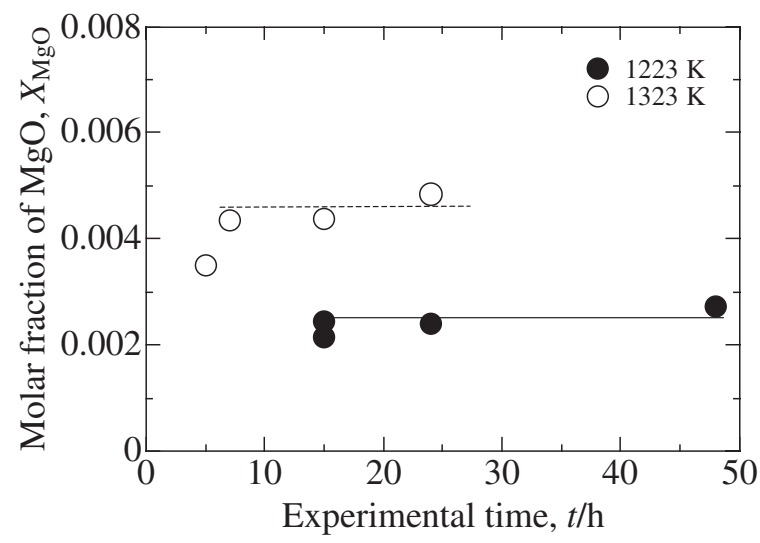

Fig. 5 Time dependence of the $\mathrm{MgO}$ solubility in molten $\mathrm{CaCl}_{2}$ at $1223 \mathrm{~K}$ and $1323 \mathrm{~K}$.

systems. This suggests that the solubility product may depend on the composition of molten salt such as $X_{\mathrm{Mg}^{2+}}$ or $X_{\mathrm{O}^{2-}}$.

Therefore, the effect of $\mathrm{CaO}$ and $\mathrm{MgCl}_{2}$ addition on the solubility product of $\mathrm{MgO}$ in the $\mathrm{CaCl}_{2}$ melt was investigated at $1373 \mathrm{~K}$. The experimental conditions and results are summarized in Tables 3 and 4, and the dependence of the solubility product on $X_{\mathrm{Mg}^{2+}}$ and $X_{\mathrm{O}^{2-}}$ are shown in Fig. 6. As seen in the figure, the solubility product is dependent on $X_{\mathrm{Mg}^{2+}}$ remarkably, whereas independent of the $X_{\mathrm{O}^{2-}}$ in the range of $X_{\mathrm{O}^{2-}}<0.05$.

\section{Discussions}

\subsection{The composition dependence of the solubility prod- uct of MgO}

The dissolution reaction of $\mathrm{MgO}$ in molten salt is represented by eq. (6) and the equilibrium constant of the reaction is expressed as eq. (7).

Table 2 Solubility of $\mathrm{MgO}$ in molten $\mathrm{CaCl}_{2}$.

\begin{tabular}{|c|c|c|c|c|c|c|}
\hline \multirow[t]{2}{*}{ No. } & \multirow[t]{2}{*}{ Temp. (K) } & \multirow[t]{2}{*}{ Time (h) } & \multirow{2}{*}{$\begin{array}{c}\begin{array}{c}\text { Initial } \\
\text { concentration }\end{array} \\
X_{\mathrm{O}^{2-}}{ }^{0} \times 10^{2}\end{array}$} & \multicolumn{2}{|c|}{$\begin{array}{l}\text { Equilibrium } \\
\text { concentration }\end{array}$} & \multirow[t]{2}{*}{$\ln X_{\mathrm{Mg}^{2+}} X_{\mathrm{O}^{2-}}$} \\
\hline & & & & $X_{\mathrm{O}^{2-}} \times 10^{2}$ & $X_{\mathrm{Mg}^{2+}} \times 10^{2}$ & \\
\hline $2-1$ & 1223 & 24 & 0 & 0.71 & 0.24 & -11.0 \\
\hline $2-2$ & 1248 & 24 & 0 & 0.75 & 0.25 & -10.9 \\
\hline $2-3$ & 1323 & 15 & 0 & 0.81 & 0.44 & -10.2 \\
\hline $2-4$ & 1373 & 15 & 0 & 0.85 & 0.42 & -10.2 \\
\hline $2-5$ & 1423 & 15 & 0 & 1.24 & 0.63 & -9.46 \\
\hline $2-6$ & 1473 & 15 & 0 & 1.55 & 0.54 & -9.39 \\
\hline $2-7$ & 1523 & 15 & 0 & 1.43 & 0.50 & -9.55 \\
\hline
\end{tabular}

Table 3 Solubility of $\mathrm{MgO}$ in the molten $\mathrm{CaCl}_{2}-\mathrm{CaO}$ system.

\begin{tabular}{|c|c|c|c|c|c|c|}
\hline \multirow[t]{2}{*}{ No. } & \multirow[t]{2}{*}{ Temp. (K) } & \multirow[t]{2}{*}{ Time (h) } & \multirow{2}{*}{$\begin{array}{c}\begin{array}{c}\text { Initial } \\
\text { concentration }\end{array} \\
X_{\mathrm{O}^{2-}}{ }^{0} \times 10^{2}\end{array}$} & \multicolumn{2}{|c|}{$\begin{array}{l}\text { Equilibrium } \\
\text { concentration }\end{array}$} & \multirow[t]{2}{*}{$\ln X_{\mathrm{Mg}^{2+}} X_{\mathrm{O}^{2-}}$} \\
\hline & & & & $X_{\mathrm{O}^{2-}} \times 10^{2}$ & $X_{\mathrm{Mg}^{2+}} \times 10^{2}$ & \\
\hline $3-2$ & 1373 & 15 & 1.22 & 1.50 & 0.092 & -11.2 \\
\hline $3-3$ & 1373 & 15 & 2.68 & 3.02 & 0.081 & -10.6 \\
\hline $3-4$ & 1373 & 15 & 5.13 & 5.42 & 0.084 & -10.0 \\
\hline
\end{tabular}


Table 4 Solubility of $\mathrm{MgO}$ in the molten $\mathrm{CaCl}_{2}-\mathrm{MgCl}_{2}$ system.

\begin{tabular}{|c|c|c|c|c|c|c|c|}
\hline \multirow[t]{2}{*}{ No. } & \multirow[t]{2}{*}{ Temp. (K) } & \multirow[t]{2}{*}{ Time (h) } & \multicolumn{2}{|c|}{$\begin{array}{c}\text { Initial } \\
\text { concentration }\end{array}$} & \multicolumn{2}{|c|}{$\begin{array}{l}\text { Equilibrium } \\
\text { concentration }\end{array}$} & \multirow[t]{2}{*}{$\ln X_{\mathrm{Mg}^{2+}} X_{\mathrm{O}^{2-}}$} \\
\hline & & & $X_{\mathrm{O}^{2-}}{ }^{0} \times 10^{2}$ & $X_{\mathrm{Mg}^{2+}}{ }^{0} \times 10^{2}$ & $X_{\mathrm{O}^{2-}} \times 10^{2}$ & $X_{\mathrm{Mg}^{2+}} \times 10^{2}$ & \\
\hline $4-2$ & 1373 & 15 & 0 & 10.2 & 1.40 & 7.13 & -6.91 \\
\hline $4-3$ & 1373 & 15 & 0 & 19.9 & 2.64 & 11.9 & -5.76 \\
\hline $4-4$ & 1373 & 15 & 0 & 30.0 & 1.07 & 21.2 & -6.09 \\
\hline
\end{tabular}

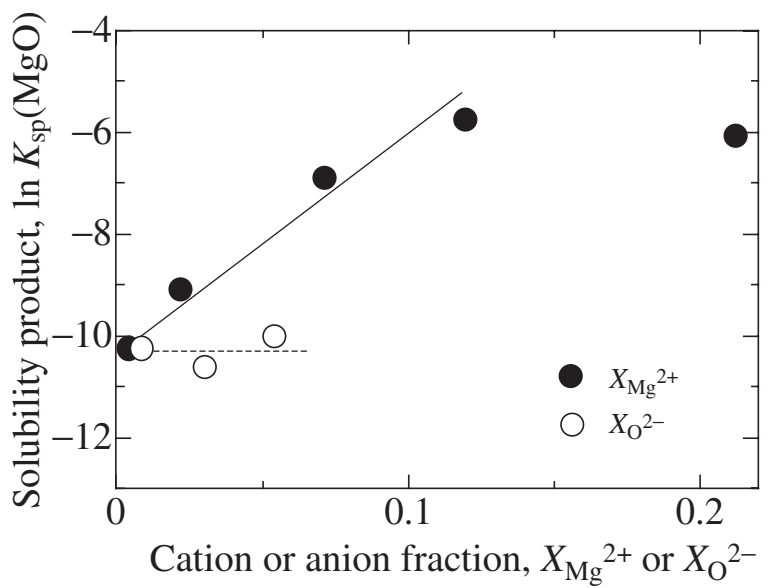

Fig. 6 Composition dependence of the solubility product of $\mathrm{MgO}$ in molten $\mathrm{CaCl}_{2}$ at $1323 \mathrm{~K}$.

$$
\begin{aligned}
& \mathrm{MgO}(\mathrm{s})=\mathrm{Mg}^{2+}+\mathrm{O}^{2-} \\
& K_{6}=\frac{a_{\mathrm{Mg}^{2+}} a_{\mathrm{O}^{2-}}}{a_{\mathrm{MgO}(\mathrm{s})}}=a_{\mathrm{Mg}^{2+}} a_{\mathrm{O}^{2-}}=\gamma_{\mathrm{Mg}^{2+}} \gamma_{\mathrm{O}^{2-}} X_{\mathrm{Mg}^{2+}} X_{\mathrm{O}^{2-}}
\end{aligned}
$$

where $a_{\mathrm{Mg}^{2+}}$ and $a_{\mathrm{O}^{2-}}$ are the activities of $\mathrm{Mg}^{2+}$ and $\mathrm{O}^{2-}$ ions, $\gamma_{\mathrm{Mg}^{2+}}$ and $\gamma_{\mathrm{O}^{2-}}$ are the activity coefficients of $\mathrm{Mg}^{2+}$ and $\mathrm{O}^{2-}$ ions, and $K_{6}$ is the equilibrium constant of reaction (6). Although we have to treat the activities of ions carefully, the standard states of $\mathrm{Mg}^{2+}$ and $\mathrm{O}^{2-}$ ions are assumed to be those of hypothetical pure liquid $\mathrm{MgO}$ in order to argue the relative change in the activity coefficient with composition.

The activities of $\mathrm{MgCl}_{2}$ and $\mathrm{CaCl}_{2}$ almost conform to ideal solution as shown in Fig. 7, which are calculated from the liquidus of the $\mathrm{MgCl}_{2}-\mathrm{CaCl}_{2}$ binary system ${ }^{8)}$ and the Gibbs energy of fusion for both components ${ }^{11)}$ using Gibbs-Duhem integration and regular solution model. The activity of $\mathrm{Mg}^{2+}$ ion is proportional to the activity of $\mathrm{MgCl}_{2}$ if the activity coefficient of $\mathrm{Cl}^{-}$ion is independent of the cation fraction $X_{\mathrm{Mg}^{2+}}$. Therefore, the activity coefficient of $\mathrm{Mg}^{2+}$ ion is considered to be constant in the system.

Using the experimental data, the composition dependence of $\gamma_{\mathrm{O}^{2-}}$ can be estimated quantitatively. The Taylor series expansion of $\ln \gamma_{\mathrm{O}^{2-}}$ at infinite dilution can be written as eq. (8), where we treated the first order terms neglecting the higher order terms due to the small $\mathrm{MgO}$ solubility in $\mathrm{CaCl}_{2}$ melt.

$$
\ln \gamma_{\mathrm{O}^{2-}}=\ln \gamma_{\mathrm{O}^{2-}}^{0}+\varepsilon X_{\mathrm{Mg}^{2+}}=\ln \gamma_{\mathrm{O}^{2-}}^{0}-66.8 X_{\mathrm{Mg}^{2+}}
$$

Here $\gamma_{\mathrm{O}^{2-}}{ }^{0}$ is the activity coefficient of $\mathrm{O}^{2-}$ ion at infinite dilution, and $\varepsilon$ is the constant, namely interaction parameter

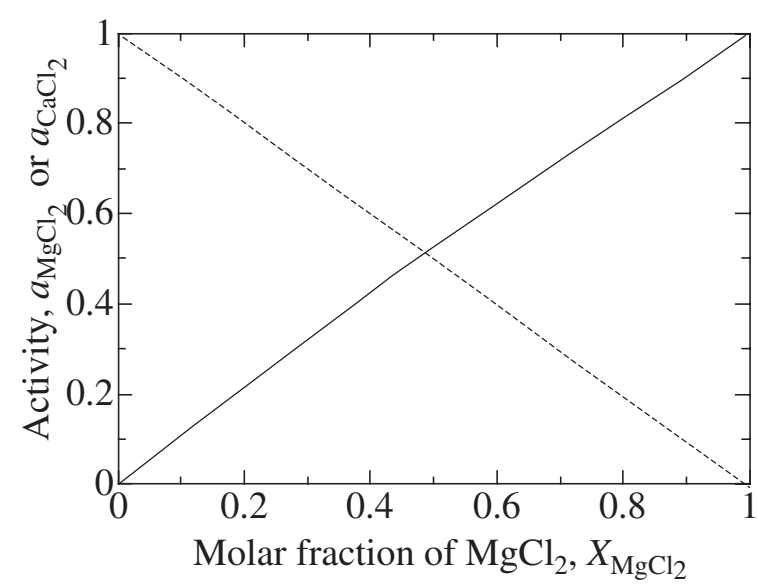

Fig. 7 Activity of $\mathrm{MgCl}_{2}$ or $\mathrm{CaCl}_{2}$ at $1373 \mathrm{~K}$ calculated from the phase diagram of the $\mathrm{MgCl}_{2}-\mathrm{CaCl}_{2}$ system.

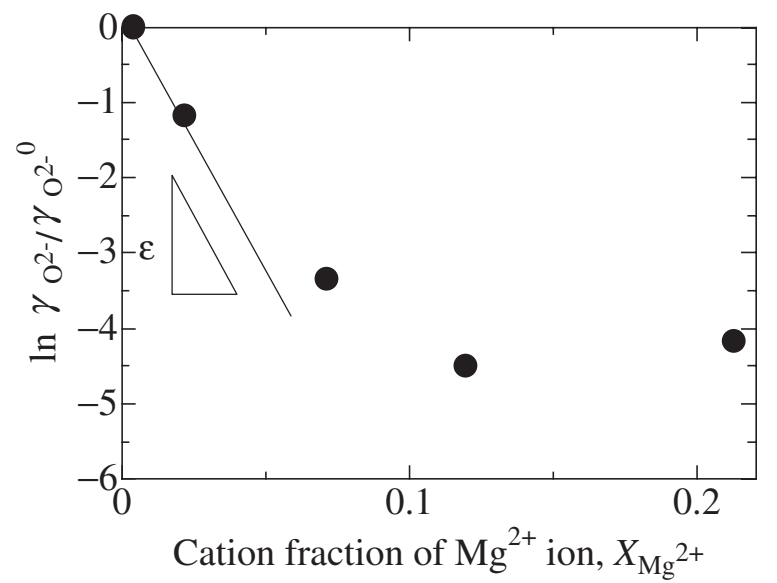

Fig. 8 Dependence of the activity coefficient of $\mathrm{O}^{2-}$ ion on the molten salt composition at $1373 \mathrm{~K}$.

between $\mathrm{Mg}^{2+}$ and $\mathrm{O}^{2-}$, which corresponds to the slope of the line in Fig. 8.

This results can be explained qualitatively by the fact that the Coulomb interaction of $\mathrm{Mg}$ and $\mathrm{O}$ is stronger than that of $\mathrm{Ca}$ and $\mathrm{O}$ in molten salt. It can be predicted from the comparison of lattice energy of solid state $\mathrm{MgO}$ and $\mathrm{CaO}$, $41.0 \mathrm{eV}$ and $36.5 \mathrm{eV}$, respectively, which were calculated by Born and Madelung. ${ }^{9)}$

Therefore, $\mathrm{O}^{2-}$ ion interacted more strongly with $\mathrm{Mg}^{2+}$ ion in molten $\mathrm{MgCl}_{2}$ than $\mathrm{Ca}^{2+}$ ion in molten $\mathrm{CaCl}_{2}$, and $\gamma_{\mathrm{O}^{2-}}$ decreases with increasing $\mathrm{Mg}^{2+}$ ion content in molten salt. 
The result of eq. (8) can be interpreted by the theory of salt mixtures with two cations and two anions based on the assumption of regular solution developed by Flood. ${ }^{10)}$ Gibbs energy of the molten salt mixture with two cations $\left(\mathrm{Mg}^{2+}\right.$, $\left.\mathrm{Ca}^{2+}\right)$ and two anion $\left(\mathrm{O}^{2-}, \mathrm{Cl}^{-}\right), G$, is represented by eq. (9).

$$
\begin{aligned}
G= & G^{0}+\Delta G^{\mathrm{M}} \\
G^{0}= & n_{\mathrm{MgO}} G_{\mathrm{MgO}(\mathrm{l})}^{0}+n_{\mathrm{CaO}} G_{\mathrm{CaO}(\mathrm{l})}^{0} \\
& +n_{\mathrm{MgCl}_{2}} G_{\mathrm{MgCl}_{2}(\mathrm{l})}^{0}+n_{\mathrm{CaCl}_{2}} G_{\mathrm{CaCl}_{2}(\mathrm{l})}^{0}
\end{aligned}
$$

where $G^{0}$ is the Gibbs energy of molten salt defined as eq. (10), $\Delta G^{\mathrm{M}}$ is the Gibbs energy of mixing, $G_{\mathrm{i}}{ }^{0}$ is the standard molar Gibbs energy of compound $\mathrm{i}$, and $n_{\mathrm{i}}$ is the numbers of moles for the compound i.

Numbers of moles for $\mathrm{Mg}^{2+}, \mathrm{Ca}^{2+}, \mathrm{O}^{2-}$ and $\mathrm{Cl}^{-}$ion in the system are represented by $n_{\mathrm{Mg}^{2+}}, n_{\mathrm{Ca}^{2+}}, n_{\mathrm{O}^{2-}}$ and $n_{\mathrm{Cl}^{-}}$, respectively, and the cation fraction $X_{\mathrm{Ca}^{2+}}$ and the anion fraction $X_{\mathrm{Cl}^{-}}$are defined as eq. (11).

$$
X_{\mathrm{Ca}^{2+}}=\frac{n_{\mathrm{Ca}^{2+}}}{n_{\mathrm{Mg}^{2+}}+n_{\mathrm{Ca}^{2+}}}, \quad X_{\mathrm{Cl}^{-}}=\frac{n_{\mathrm{Cl}^{-}}}{n_{\mathrm{O}^{2-}}+n_{\mathrm{Cl}^{-}}}
$$

The condition of electroneutrality demands the following restriction.

$$
n_{\mathrm{Mg}^{2+}}+n_{\mathrm{Ca}^{2+}}=n_{\mathrm{O}^{2-}}+\frac{1}{2} n_{\mathrm{Cl}^{-}}
$$

If the cations are randomly arranged on cation sites and the anions on anion sites, $G^{0}$ and $\Delta G^{\mathrm{M}}$ can be represented by eqs. (13)-(16).

$$
\begin{aligned}
G^{0}= & n_{\mathrm{O}^{2-}} X_{\mathrm{Mg}^{2+}} G_{\mathrm{MgO}(\mathrm{l})}^{0}+n_{\mathrm{O}^{2-}} X_{\mathrm{Ca}^{2+}} G_{\mathrm{CaO}(\mathrm{l})}^{0} \\
& +\frac{1}{2} n_{\mathrm{Cl}^{-}} X_{\mathrm{Mg}^{2+}} G_{\mathrm{MgCl}_{2}(1)}^{0}+\frac{1}{2} n_{\mathrm{Cl}^{-}} X_{\mathrm{Ca}^{2+}} G_{\mathrm{CaCl}_{2}(\mathrm{l})}^{0} \\
\Delta G^{\mathrm{M}}= & \Delta H^{\mathrm{M}}-T \Delta S^{\mathrm{M}} \\
\Delta H^{\mathrm{M}}= & \Omega X_{\mathrm{MgO}} X_{\mathrm{CaCl}_{2}}=\Omega X_{\mathrm{Mg}^{2+}} X_{\mathrm{Ca}^{2+}} \\
\Delta S^{\mathrm{M}}= & -R\left(n_{\mathrm{Mg}^{2+}} \ln X_{\mathrm{Mg}^{2+}}+n_{\mathrm{Ca}^{2+}} \ln X_{\mathrm{Ca}^{2+}}\right. \\
& \left.+n_{\mathrm{O}^{2-}} \ln X_{\mathrm{O}^{2-}}+n_{\mathrm{Cl}^{-}} \ln X_{\mathrm{Cl}^{-}}\right)
\end{aligned}
$$

In eq. (15), $\Omega$ is the constant value independent of the salt composition.

Therefore, the partial molar Gibbs energy is calculated by eq. (17).

$$
\begin{aligned}
& \bar{G}_{\mathrm{MgO}(\mathrm{l})}=\left(\frac{\partial G}{\partial n_{\mathrm{MgO}}}\right)_{n_{\mathrm{CaCl}_{2}}}=\left(\frac{\partial G}{\partial n_{\mathrm{Mg}^{2+}}}\right)_{n_{\mathrm{Ca}^{2+}, n_{\mathrm{Cl}^{-}}}} \\
&= G_{\mathrm{MgO}(\mathrm{l})}^{0}+\frac{n_{\mathrm{Cl}^{-}}}{n_{\mathrm{Cl}^{-}}+2 n_{\mathrm{O}^{2-}}} X_{\mathrm{Ca}^{2+}} \Delta G_{18}^{0} \\
&+R T \ln X_{\mathrm{Mg}^{2+}} X_{\mathrm{O}^{2-}}+\Omega X_{\mathrm{Ca}^{2+}}^{2} \\
& \mathrm{MgO}(1)+\mathrm{CaCl}_{2}(1)=\mathrm{CaO}(1)+\mathrm{MgCl}_{2}(1)
\end{aligned}
$$

Here $\Delta G^{0}{ }_{18}$ is the standard Gibbs energy change of the chemical reaction (18) and this value is $87320 \mathrm{~J} / \mathrm{mol}$ at $1373 \mathrm{~K}^{11,12)}$

If we consider only the infinite dilute range of $\mathrm{MgO}$, we may assume $n_{\mathrm{O}^{2-}}$ and $X_{\mathrm{Mg}^{2+}}{ }^{2}$ in eq. (17) are considerably small. Hence, the following approximations can be developed.

$$
\begin{aligned}
& \frac{n_{\mathrm{Cl}^{-}}}{n_{\mathrm{Cl}^{-}}+2 n_{\mathrm{O}^{2-}}}=\frac{1}{1+2 n_{\mathrm{O}^{2-}} / n_{\mathrm{Cl}^{-}}} \cong 1 \\
& X_{\mathrm{Ca}^{2+}}{ }^{2}=\left(1-X_{\mathrm{Mg}^{2+}}\right)^{2} \cong 1-2 X_{\mathrm{Mg}^{2+}}
\end{aligned}
$$

Therefore, the relative partial molar Gibbs energy of $\mathrm{MgO}$ can be calculated by eq. (21).

$$
\begin{aligned}
\Delta \bar{G}_{\mathrm{MgO}(\mathrm{l})}= & \bar{G}_{\mathrm{MgO}(\mathrm{l})}-G_{\mathrm{MgO}(\mathrm{l})}^{0}=R T \ln a_{\mathrm{MgO}(\mathrm{l})} \\
= & -\left(\Delta G_{18}^{0}+2 \Omega\right) X_{\mathrm{Mg}^{2+}}+R T \ln X_{\mathrm{Mg}^{2+}} X_{\mathrm{O}^{2-}} \\
& +\left(\Delta G_{18}^{0}+\Omega\right)
\end{aligned}
$$

The activity of $\mathrm{MgO}$ is written as eq. (22).

$$
a_{\mathrm{MgO}(1)}=K a_{\mathrm{Mg}^{2+}} a_{\mathrm{O}^{2-}}=K \gamma_{\mathrm{Mg}^{2+}}^{0} \gamma_{\mathrm{O}^{2-}} X_{\mathrm{Mg}^{2+}} X_{\mathrm{O}^{2-}}
$$

where $K$ is a constant value independent of the composition of molten salt, and $\gamma_{\mathrm{Mg}^{2+}}{ }^{0}$ is the activity coefficient of $\mathrm{Mg}^{2+}$ ion, which is constant as mentioned above. From eqs. (21) and (22), eq. (23) can be obtained.

$$
\begin{aligned}
\ln \gamma_{\mathrm{O}^{2-}}= & -\frac{\Delta G_{18}^{0}+2 \Omega}{R T} X_{\mathrm{Mg}^{2+}} \\
& +\frac{\Delta G_{18}^{0}+\Omega}{R T}-\ln K \gamma_{\mathrm{Mg}^{2+}}^{0}
\end{aligned}
$$

Therefore, the constant value $\varepsilon$ defined in eq. (8) becomes

$$
\varepsilon=-\frac{\Delta G_{18}^{0}+2 \Omega}{R T}
$$

The parameter $\Omega$ can be evaluated from the present work.

$$
\Omega=338000[\mathrm{~J} / \mathrm{mol}]
$$

Hence, the reason of the small solubility of $\mathrm{MgO}$ in molten $\mathrm{CaCl}_{2}$ is because the enthalpy of mixing for the $\mathrm{MgO}-\mathrm{CaCl}_{2}$ system is very large.

\subsection{Possibility of the corrosion of the refractories}

Using the present results, the possibility of corrosion of $\mathrm{MgO}$ refractory will be evaluated with some assumption. When the refractory of the furnace, where chlorine containing wastes are treated, consists of pure $\mathrm{MgO}$ and molten $\mathrm{CaO}-\mathrm{SiO}_{2}-\mathrm{Al}_{2} \mathrm{O}_{3}$ slag is in equilibrium with gas phase, two types of corrosion by $\mathrm{HCl}$ and $\mathrm{CaCl}_{2}$ in the gas phase can be considered. To start with the case of $\mathrm{HCl}$ corrosion, the value of $P_{\mathrm{HCl}^{2}}{ }^{2} / P_{\mathrm{H}_{2} \mathrm{O}}$ of the gas phase in equilibrium with molten slag at $1748 \mathrm{~K}$ can be derived by eq. (26), where $P_{\mathrm{HCl}}$ and $P_{\mathrm{H}_{2} \mathrm{O}}$ are the partial pressures of $\mathrm{HCl}$ and $\mathrm{H}_{2} \mathrm{O}$ in the furnace, respectively.

$$
\begin{aligned}
& \frac{P_{\mathrm{HCl}^{2}}}{P_{\mathrm{H}_{2} \mathrm{O}}}=\frac{\left[\text { mass } \% \mathrm{Cl}^{-}\right]^{2}}{C_{\mathrm{Cl}^{-}}{ }^{2}} \exp \left(-\frac{2 \Delta G_{27}^{0}}{1748 R}\right) \\
& \frac{1}{2} \mathrm{H}_{2} \mathrm{O}(\mathrm{g})+\frac{1}{2} \mathrm{Cl}_{2}(\mathrm{~g})=\mathrm{HCl}(\mathrm{g})+\frac{1}{4} \mathrm{O}_{2}(\mathrm{~g}) \\
& \Delta G_{27}^{0}=29620-34.30 T[\mathrm{~J} / \mathrm{mol}]^{11)}
\end{aligned}
$$

Here $R$ is the gas constant and its value is $8.314 \mathrm{~J} / \mathrm{mol} \cdot \mathrm{K}$, [mass $\% \mathrm{Cl}^{-}$] is the solubility of chlorine in the slag, $C_{\mathrm{Cl}^{-}}$is chloride capacity defined by Hirosumi et al. ${ }^{3)}$ and $\Delta G^{0}{ }_{27}$ is the standard Gibbs energy change of the reaction (27).

The reaction between solid $\mathrm{MgO}$ and $\mathrm{HCl}$ gas is written as eq. (29). 


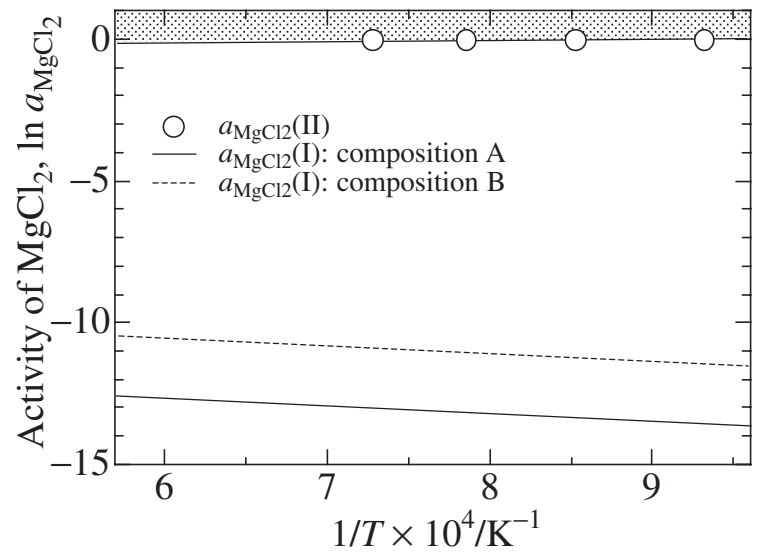

Fig. 9 Temperature dependence of $a_{\mathrm{MgCl}_{2}}$ in gas phase at the surface of refractories. (The gas phase is in equilibrium with the slag of composition A or B at $1748 \mathrm{~K}$.)

$$
\begin{aligned}
& \mathrm{MgO}(\mathrm{s})+2 \mathrm{HCl}(\mathrm{g})=\mathrm{H}_{2} \mathrm{O}(\mathrm{g})+\mathrm{MgCl}_{2}(\mathrm{l}) \\
& \Delta G_{29}^{0}=21110+22.32 T[\mathrm{~J} / \mathrm{mol}]^{11)}
\end{aligned}
$$

where $\Delta G_{29}^{0}$ is the standard Gibbs energy change of the reaction (29). In equilibrium state, the activity of $\mathrm{MgCl}_{2}$ is represented by eq. (31).

$$
a_{\mathrm{MgCl}_{2}}=\frac{P_{\mathrm{HCl}^{2}}^{2}}{P_{\mathrm{H}_{2} \mathrm{O}}} \exp \left(-\frac{\Delta G_{29}^{0}}{R T}\right)
$$

When the $P_{\mathrm{HCl}^{2}}{ }^{2} / P_{\mathrm{H}_{2} \mathrm{O}}$ is uniform in the furnace, the activity of $\mathrm{MgCl}_{2}$ at the refractory surface can be calculated by eqs. (26) and (31).

On the other hand, the activity of $\mathrm{MgCl}_{2}$ in $\mathrm{MgCl}_{2}$ salt in equilibrium with solid $\mathrm{MgO}$ is close to molar fraction of $\mathrm{MgCl}_{2}$ because the solubility of $\mathrm{MgO}$ in the melt is very small.

Temperature dependence of the activity of $\mathrm{MgCl}_{2}$ calculated by eq. (31), $a_{\mathrm{MgCl}_{2}}(\mathrm{I})$, and that of the salt in equilibrium with solid $\mathrm{MgO}, a_{\mathrm{MgCl}_{2}}(\mathrm{II})$, are shown in Fig. 9. Two typical slag compositions, $\mathrm{CaO}: \mathrm{SiO}_{2}: \mathrm{Al}_{2} \mathrm{O}_{3}=52.2: 0: 47.8$ (composition A) and $\mathrm{CaO}: \mathrm{SiO}_{2}: \mathrm{Al}_{2} \mathrm{O}_{3}=32.0: 48.9: 19.1$ (composition B) were selected, containing 0.1 mass $\% \mathrm{Cl}^{-}$at $1748 \mathrm{~K}$. Chloride capacities for both slags are known as 58.4, and 20.1. ${ }^{3)}$ From the present calculation, $\mathrm{MgO}$ corrosion which produces the liquid $\mathrm{MgCl}_{2}$ on its surface will not occur at any temperature for the activity of $\mathrm{MgCl}_{2}$ in the furnace is smaller than that of the salt in equilibrium with solid $\mathrm{MgO}$.

Secondly, the possibility of corrosion by $\mathrm{CaCl}_{2}$ gas is considered. $P_{\mathrm{CaCl}_{2}}$ of the gas phase in equilibrium with molten slag at $1748 \mathrm{~K}$ can be derived by eq. (32).

$$
\begin{aligned}
& P_{\mathrm{CaCl}_{2}}=\frac{\left[\mathrm{mass} \% \mathrm{Cl}^{-}\right]^{2} a_{\mathrm{CaO}}}{C_{\mathrm{Cl}^{-}}{ }^{2}} \exp \left(-\frac{2 \Delta G_{33}^{0}}{R T}\right) \\
& \frac{1}{2} \mathrm{CaO}(\mathrm{l})+\frac{1}{2} \mathrm{Cl}_{2}(\mathrm{~g})=\frac{1}{2} \mathrm{CaCl}_{2}(\mathrm{~g})+\frac{1}{4} \mathrm{O}_{2}(\mathrm{~g}) \\
& \Delta G_{33}^{0}=-1379-22.15 T[\mathrm{~J} / \mathrm{mol}]^{11)}
\end{aligned}
$$

Here $a_{\mathrm{CaO}}$ is the activity of $\mathrm{CaO}$ in the slag, $\Delta G^{0}{ }_{33}$ is the standard Gibbs energy change of the reaction (33).

When $P_{\mathrm{CaCl}_{2}}$ is assumed to be uniform in the furnace, the activity of $\mathrm{CaCl}_{2}$ relative to the pure liquid $\mathrm{CaCl}_{2}$ at the

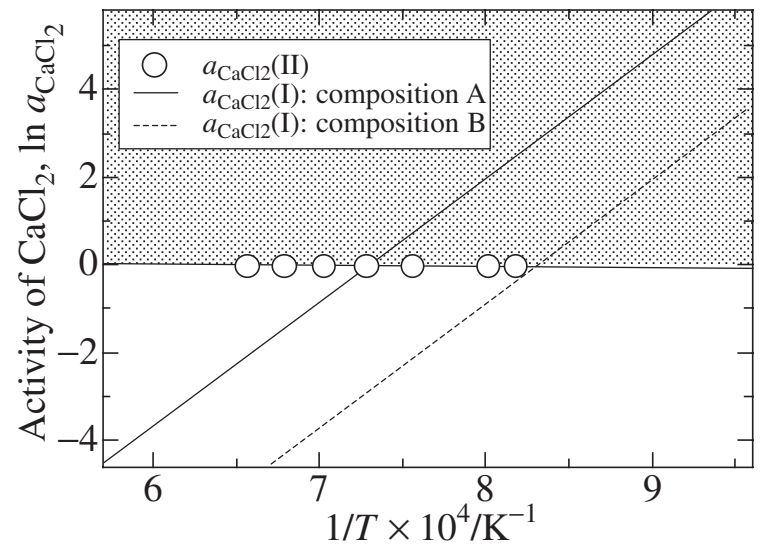

Fig. 10 Temperature dependence of $a_{\mathrm{CaCl}_{2}}$ in gas phase at the surface of refractories. (The gas phase is in equilibrium with the slag of composition A or B at $1748 \mathrm{~K}$.)

refractory surface can be obtained as follows.

$$
\begin{aligned}
& \mathrm{CaCl}_{2}(\mathrm{l})=\mathrm{CaCl}_{2}(\mathrm{~g}) \\
& \Delta G_{35}^{0}=234900-106.3 T[\mathrm{~J} / \mathrm{mol}]^{11)}
\end{aligned}
$$

The activity of $\mathrm{CaCl}_{2}$ relative to pure liquid $\mathrm{CaCl}_{2}$ in equilibrium with solid $\mathrm{MgO}$ is represented by eq. (37) when Temkin's model is assumed to be valid.

$$
a_{\mathrm{CaCl}_{2}}=X_{\mathrm{Ca}^{2+}} X_{\mathrm{Ca}^{-}}{ }^{2}
$$

Temperature dependence of the activity of $\mathrm{CaCl}_{2}$ relative to pure liquid $\mathrm{CaCl}_{2}$ in gas phase, $a_{\mathrm{CaCl}_{2}}(\mathrm{I})$, and that of the salt in equilibrium with solid $\mathrm{MgO}, a_{\mathrm{CaCl}_{2}}$ (II), is shown in Fig. 10. In this calculation, the condition was selected as $\left[\operatorname{mass} \% \mathrm{Cl}^{-}\right]=0.1, C_{\mathrm{Cl}^{-}}=58.4$ and $20.1, a_{\mathrm{CaO}}=0.50$ and $3.5 \times 10^{-3}$ which corresponds to the activity data at $1823 \mathrm{~K}$ for the slags of composition $\mathrm{A}$ and $\mathrm{B} .{ }^{13)}$

If $a_{\mathrm{CaCl}_{2}}$ (I) is larger than $a_{\mathrm{CaCl}_{2}}$ (II), solid $\mathrm{MgO}$ can be corroded by dissolution of $\mathrm{MgO}$ in molten $\mathrm{CaCl}_{2}$. As shown in Fig. 10, this type of corrosion occurs at less than $1350 \mathrm{~K}$ for composition $\mathrm{A}$ and at less than $1200 \mathrm{~K}$ for composition $\mathrm{B}$.

Hereafter, the corrosion temperature $T_{\text {corr }}$ is defined as the temperature below which $a_{\mathrm{CaCl}_{2}}$ (I) is larger than $a_{\mathrm{CaCl}_{2}}$ (II) and the dependence of $T_{\text {corr }}$ on the $\mathrm{Cl}$ content in the slag is shown in Fig. 11. Even a small amount of chlorine in the slag is

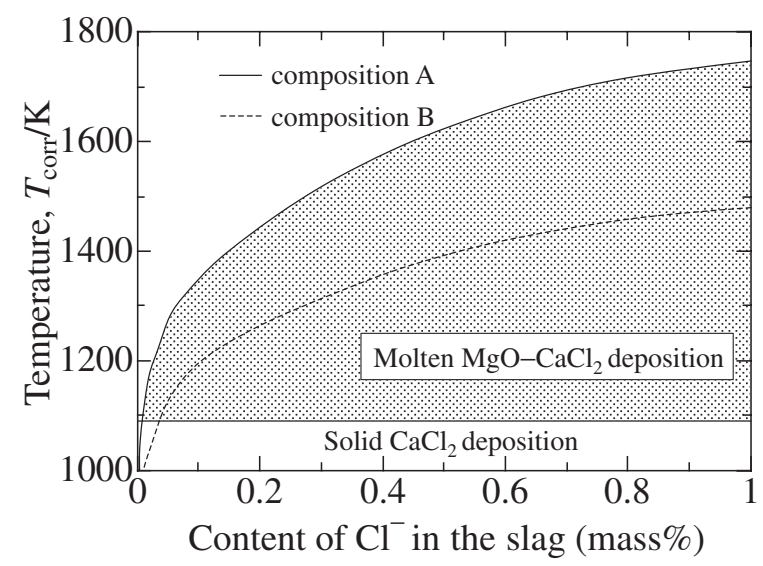

Fig. 11 Relationship between $T_{\text {corr }}$ and [mass $\% \mathrm{Cl}^{-}$]. 
shown to cause the corrosion of $\mathrm{MgO}$ refractory by the dissolution in molten $\mathrm{CaCl}_{2}$ thermodynamically.

\section{Conclusions}

The solubility of $\mathrm{MgO}$ in the $\mathrm{MgCl}_{2}-\mathrm{CaCl}_{2}$ system was measured and the following findings were obtained.

(1) The $\mathrm{MgO}$ solubility product in $\mathrm{MgCl}_{2}$ melt was larger than that in $\mathrm{CaCl}_{2}$ melt, and the temperature dependences of them were represented by the following equations, respectively.

$$
\begin{aligned}
\ln K_{\mathrm{sp}}(\mathrm{MgO}) & =\ln X_{\mathrm{Mg}^{2+}} X_{\mathrm{O}^{2-}} \\
& \left.=-\frac{7400}{T}+1.26 \quad \text { (in molten } \mathrm{MgCl}_{2}\right) \\
\ln K_{\mathrm{sp}}(\mathrm{MgO}) & =\ln X_{\mathrm{Mg}^{2+}} X_{\mathrm{O}^{2-}} \\
& \left.=-\frac{10400}{T}-2.44 \quad \text { (in molten } \mathrm{CaCl}_{2}\right)
\end{aligned}
$$

(2) The solubility product of $\mathrm{MgO}$ in molten $\mathrm{CaCl}_{2}$ increased with the content of $\mathrm{Mg}^{2+}$ ion in the salt. This dependence was considered to be due to the difference in the interaction between $\mathrm{Mg}-\mathrm{O}$ and $\mathrm{Ca}-\mathrm{O}$.

(3) Some types of corrosion of $\mathrm{MgO}$ were discussed, and it was predicted that $\mathrm{MgO}$ corrosion by the dissolution of $\mathrm{MgO}$ in molten $\mathrm{CaCl}_{2}$ could happen at low temperature area.

\section{REFERENCES}

1) K. Wakimoto, H. Nakamura, M. Fujii, Y. Yamada, K. Nemoto and K. Tomioka: NKK Tech. Rep. 160 (1997) 1-6.

2) M. Asanuma, T. Ariyama, M. Iemoto, S. Wakamatsu, S. Masuko and K. Suyama: J. Chem. Eng. Jpn. 27 (2001) 326-334.

3) T. Hirosumi and K. Morita: ISIJ Int. 40 (2000) 943-948.

4) M. Miwa and K. Morita: ISIJ Int. 42 (2002) 1065-1070.

5) R. L. Martin and J. B. West: J. Inorg. Nucl. Chem. 24 (1962) 105-111.

6) S. Boghosian, Aa. Godo, H. Mediaas, W. Ravlo and T. Ostvold: Acta Chem. Scand. 45 (1991) 145-157.

7) H. Mediaas, J. E. Vindstad and T. Ostvold: Acta Chem. Scand. 51 (1997) 504-514.

8) R. S. Roth, T. Negas and L. P. Cook: Phase Diagram for Ceramists Vol. 5, (The American Ceramic Society, 1983) 39.

9) A. J. Dekker: Solid State Physics, (Prentice-Hall, Englewood Cliffs, N. J., 1957) 122 .

10) J. Lumsden: Thermodynamics of Molten Salt Mixtures, (Academic Press, New York, 1966) 151-156.

11) E. T. Turkdogan: Physical Chemistry of High Temperature Technology, (Academic Press, New York, 1980) 5-26.

12) I. Barin: Thermochemical Data of Pure Substances Part II, (VCH, Weinheim, 1989) 857.

13) K. C. Mills: Slag Atlas 2nd Edition, (Verlag Stahleisen, Düsseldorf, 1995) 238. 